\title{
Structural change of the frustule of diatom by thermal treatment
}

\author{
Akane Arasuna* ${ }^{*}$ and Masayuki Okuno
}

\begin{abstract}
The external skeleton, frustule, of a diatom is composed of hydrous amorphous silica and amino acids. In this study, the structural changes in the frustule of Chaetoceros calcitrans after thermal treatment up to $120{ }^{\circ} \mathrm{C}$ were investigated using X-ray diffraction and attenuated total reflection infrared spectroscopy and Raman spectroscopy. Their structural changes after thermal treatment give important information to elucidate the unheated structure of the frustule and its crystallization process. In addition, this study is almost the first report to discuss the structure of diatom frustule in detail with Raman spectrum. The unheated structure of the frustule has the relatively ordered and dominant sixmembered ring structure made of $\mathrm{SiO}_{4}$ tetrahedra. The sample heated at $800{ }^{\circ} \mathrm{C}$ has the more ordered six-membered ring structure observed in quartz or cristobalite. Water molecules and silanol ( $\mathrm{Si}-\mathrm{OH})$ included in the frustule are dehydrated at this temperature. This dehydration may promote the formation of ordered and polymerized structure. The structure of the frustule after heating at $1200^{\circ} \mathrm{C}$ is similar to that of low-cristobalite. However, additional heating is required for complete crystallization.
\end{abstract}

Keywords: Diatom, Frustule, Amorphous silica, Thermal treatment, Quartz, Cristobalite, Ring structure

\section{Background}

Diatoms are extremely prosperous algae that exist in a variety of water environments (freshwater, brackishwater, and seawater). Diatom has an external skeleton called a frustule, which is composed of hydrous amorphous silica formed by precipitation of silica within silica deposition of vesicle during cell division (Vrieling et al. 1999a, 1999b). The system of bio-silicification in the frustule is related to silaffins which can precipitate of silica and generate silica nanospheres (Kröger et al. 1999).

On the other hand, the information of network fashion of $\mathrm{SiO}_{4}$ tetrahedra is useful to know characteristics of diatom frustule. But, the studies on these structures of silica in frustules were very limited. Gendron-Badou et al. (2003) revealed that the frustules of living and fossil diatoms have a de-polymerized amorphous silica network structure due to the presence of silanol (Si-OH) using nuclear magnetic resonance (NMR) and infrared (IR) spectroscopies. However, the information on the

\footnotetext{
*Correspondence: aarasuna@staff.kanazawa-u.ac.jp

Faculty of Natural System, Institute of Science and Engineering, Kanazawa University, Kakuma, Kanazawa, Ishikawa 920-1192, Japan
}

nanostructure of frustule, especially ring structure which made of $\mathrm{SiO}_{4}$ tetrahedra, is not sufficient. Raman spectroscopy could give information of the ring structure in amorphous silica materials. For example, four-membered ring is prominent in the structure of hydrous amorphous silica, synthetic opal and silica gel (Kamiya and Nasu 1998; Arasuna et al. 2013). This ring structure is characterized by the strong Raman band around $v=480 \mathrm{~cm}^{-1}$ attributed breathing mode for four-membered ring of $\mathrm{SiO}_{4}$ tetrahedra denoted as $\mathrm{D}_{1}$ band (Galeener 1982a, $1982 \mathrm{~b})$. On the other hand, silica glass which is mainly composed of six-membered ring (Shimada et al. 2002) has the strong broad Raman band around $v=430$ $460 \mathrm{~cm}^{-1}$ attributed to the $\mathrm{Si}-\mathrm{O}-\mathrm{Si}$ symmetric stretching band of six-membered ring (Galeener and Geissberger 1983; Sharma et al. 1984; Okuno et al. 1999). This broad band is not prominent in the spectra of silica gel and synthetic opal. It is very interesting that the distribution of the ring structure constituting the amorphous silica show large variation for different silica material. However, no previous studies have used Raman spectroscopic analysis to conduct a detailed structural study for the diatom frustule. This may be due to the thinness of the frustule 
through which the laser transmits to the underlying substrate. Also, the strong luminescence often occurs during Raman measurement prevents to obtain clear Raman signal. The information of the ring structure in the frustule is also important to understand the structural change of the frustule during diagenesis described as following.

The frustules of diatom are changed to opal-CT and quartz by deposition on the sea floor and successive metamorphism (Isaacs 1982). Although the high possibility that there is a difference in the structure among the amorphous silica materials as mentioned above, there is no research to elucidate the process of structural change of frustule with paying attention to details of the amorphous structure of diatom, especially its ring structure. It is thought that siliceous materials such as diatom frustules greatly affect the formation of the crust and the surface of the earth. Therefore, it is important for geologists to clarify the conversion process of diatom frustule under temperature to elucidate changes of the earth's surface and topography. In addition, the structural changes of the accumulated hydrous amorphous silica to silica glass or crystalline material are expected to provide information useful for material development at low-temperature condition in the study of material science.

In this study, the structural changes of diatom frustules after thermal treatment up to $1200{ }^{\circ} \mathrm{C}$ are elucidated using X-ray diffraction (XRD) measurement and attenuated total reflection infrared (ATR-IR) and Raman spectroscopic analyses. Raman spectroscopic analysis will give important structural information such as the ring structure in the diatom frustule. Convenient $\mathrm{KBr}$ pellet IR spectroscopy is not suitable for precise analysis for water species. Therefore, we use ATR-IR spectroscopy for obtaining precise information on water species and the information on the silica network structure after thermal treatment. XRD measurement may give information for average nanostructure of the frustule and its crystallization process by heat treatment. Our results provide important information about the unheated nanostructure of the frustules and the transformation processes of frustule during diagenesis.

\section{Experimental}

\section{Specimen}

The seawater diatom, Chaetoceros calcitrans, (cultured by Marinetech Co., Ltd) was used in this study. The components of a culture solution of diatom were sodium nitrate, ammonium sulfate, potassium dihydrogen phosphate, sodium metasilicate nonahydrate (silicon source), a trace metal such as Fe-EDTA, vitamin group, and artificial seawater.

SEM micrograph of original sample is shown in Fig. 1. SEM observation of this sample was performed

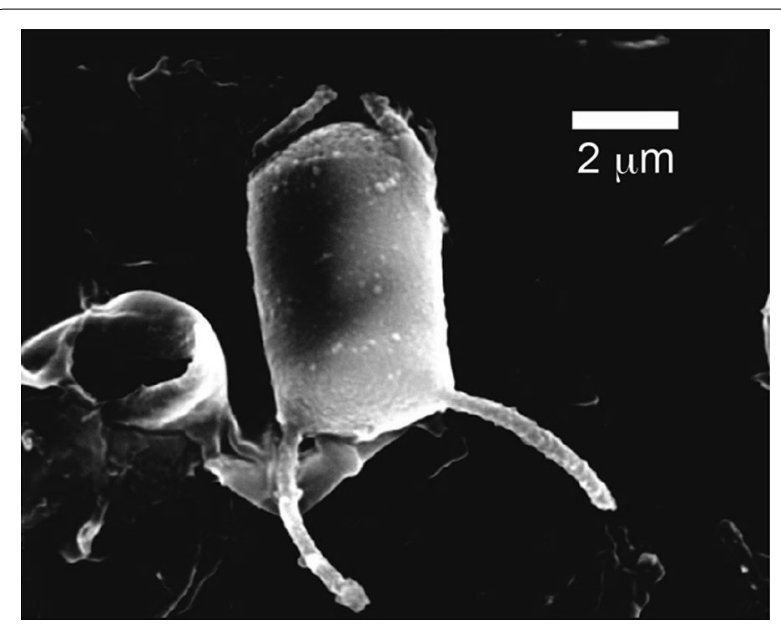

Fig. 1 The SEM micrograph of non-bleached Chaetoceros calcitrans

using JCM-6010LV (JEOL). Samples were mounted on brass specimen supports and coated with gold. SEM observations were conducted with accelerating voltage of $20 \mathrm{kV}$.

The heat treatments and successive analyses need several tenth $\mathrm{mg}$ of the diatom sample. However, it is not easy to obtain the natural diatom enough for these experiments. The diatom cultured in our laboratory was not enough for this study. Fortunately, several Japanese companies have succeeded in cultivating Chaetoceros calcitrans as a valuable feed for aquaculture (Yamauchi 2003). For this reason, we purchased the cultured diatoms that can be continuously and stably procured.

Chaetoceros calcitrans were washed in distilled water by centrifugation at $3000 \mathrm{rpm}$ for $20 \mathrm{~min}$ and dried at $30{ }^{\circ} \mathrm{C}$ for $48 \mathrm{~h}$ for desalination. The centrifugation was repeated five times. During the centrifugations, the frustule lost its original figure (It does not affect the nanostructure). In addition, to complete the removal of organic matter, the desalted samples were powdered. The Pipe Unish method (Inagaki 2011 and references therein) was adopted for the removal of organic matter. The Pipe Unish is a commercial cleaning solution including hypochlorite and the sodium hydroxide. $50 \mathrm{mg}$ of desalinated frustule, $10 \mathrm{ml}$ of distilled water and $2 \mu \mathrm{l}$ of Pipe Unish were stirred together for $20 \mathrm{~min}$. At first, the solution containing frustules from which organic matter had been removed was centrifuged at $2000 \mathrm{rpm}$ for $10 \mathrm{~min}$, and then the frustules from which organic material had been removed were washed in distilled water by centrifugation at $2000 \mathrm{rpm}$ for $10 \mathrm{~min}$. The centrifugation was repeated four times. All centrifugations were conducted at room temperature. The resulting sample was referred 
to as the "bleached sample". In this study, silica gel, one of hydrated amorphous silica material, synthesized using the sol-gel method (Arasuna et al. 2016) was used as the reference material.

\section{Thermal treatment}

The $5 \mathrm{mg}$ of powdery bleached samples were heated at $600,800,1000$, and $1200{ }^{\circ} \mathrm{C}$ for $1 \mathrm{~h}$ using an electric furnace and quenched by turning off the electric power. The range of heating temperature was decided with reference to those of the heating experiments for synthetic opal (Arasuna et al. 2013) and pennate diatom (Okuno et al. 2003). Heat experiments on synthesized hydrated amorphous opal showed that water molecule and silanol groups disappeared at around $600{ }^{\circ} \mathrm{C}$ (Arasuna et al. 2013). Moreover, the ring structure was thermally reconstituted near $1000{ }^{\circ} \mathrm{C}$ and the sample crystalized to low-cristobalite at $1200{ }^{\circ} \mathrm{C}$. Okuno et al. (2003) reported the change of $\mathrm{SiO}_{4}$ tetrahedra and their network structure in the frustule of pennate diatom by heat treatment up to $1000{ }^{\circ} \mathrm{C}$. But they conducted only IR analysis for the heated sample, the details of the complicated structural change did not become clear.

Ca. $2 \mathrm{mg}$ of the heated sample and $5 \mathrm{mg}$ of the bleached sample and silica gel were provided for the XRD analysis. For ATR-IR and Raman analyses, it was possible to measure it with the samples of about $1 \mathrm{mg}$ or less.

\section{XRD measurement}

The XRD measurements of the samples were obtained using a Rigaku RINT 2200 with $\mathrm{Cu} \mathrm{K} \alpha$ radiation. The $\theta-2 \theta$ scanning technique was used over a range of $2 \theta=2^{\circ}-60^{\circ}$ with a scan step of $0.1^{\circ}$ for all samples. The applied acceleration voltage and current were $40 \mathrm{kV}$ and $30 \mathrm{~mA}$, respectively.

\section{ATR-IR measurement}

The ATR-IR spectra were recorded using a Thermo Scientific Nicolet iS10 instrument equipped with a diamond crystal. Spectra of all samples were recorded in the range of $v=525-4000 \mathrm{~cm}^{-1}$ with a band path of $4 \mathrm{~cm}^{-1}$. The cumulative number of each measurement was 32 .

\section{Raman measurement}

The Raman spectra for samples were recorded using micro-Raman spectrometer (Horiba Jovin Yvon LabRAM HR800). The $v=514.5 \mathrm{~nm}$ line (green) of an $\mathrm{Ar}^{+}$laser light was used to excite Raman scattering, and the Raman light was collected in the back scattering geometry. The pixel resolution of our Raman spectrometer was $1.78 \mathrm{~cm}^{-1}$ pixel $^{-1}$. All observed Raman spectra were corrected for background.

\section{Results}

\section{XRD analysis}

The XRD profiles of the bleached sample and silica gel are essentially similar and show only a diffuse scattering maximum centered at around $2 \theta=22.5-23.0^{\circ}$ without crystalline peaks (Fig. 2). A broad shoulder can be observed at around $2 \theta=5^{\circ}$ in the XRD profile of the bleached sample. Similar diatom samples were investigated by Inagaki (2011), who considered this effect to be due to the remaining organic material, even after chemical treatment.

With thermal treatment at $800{ }^{\circ} \mathrm{C}$, the XRD profile shows the weak diffraction peaks at around $2 \theta=31^{\circ}$ and $35-36^{\circ}$ (Fig. 2). Moreover, the sample heated at $1000{ }^{\circ} \mathrm{C}$ shows peaks at around $2 \theta=22^{\circ}, 28^{\circ}, 30-31^{\circ}$ and $35.6^{\circ}$. The XRD profile of the sample heated at $1200{ }^{\circ} \mathrm{C}$ shows sharp diffraction peaks that basically correspond to those of low-cristobalite (Graetsch 1994).

\section{ATR-IR spectroscopic analysis}

The ATR-IR spectra for silica gel, bleached sample and heated samples are shown in Fig. 3. The ATR-IR spectrum for the bleached sample has bands at $v=800$ and $1020 \mathrm{~cm}^{-1}$, which are attributed to the $\mathrm{Si}-\mathrm{O}-\mathrm{Si}$ bending vibration and the $\mathrm{Si}-\mathrm{O}$ stretching mode, respectively (Handke and Mozgawa 1993). The weak band at around $v=1650 \mathrm{~cm}^{-1}$ can be assigned to the $\mathrm{H}-\mathrm{O}-\mathrm{H}$ bending vibration (Benesi and Jones 1959). A broad band appeared at around $v=3000-3700 \mathrm{~cm}^{-1}$, which could be

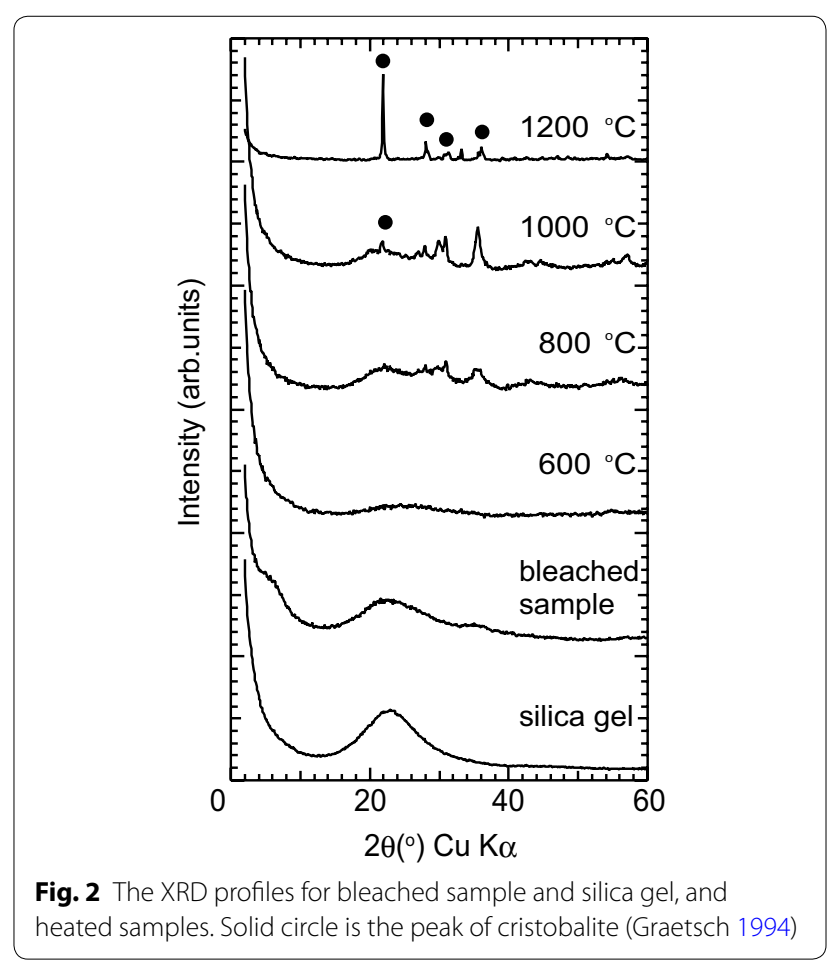




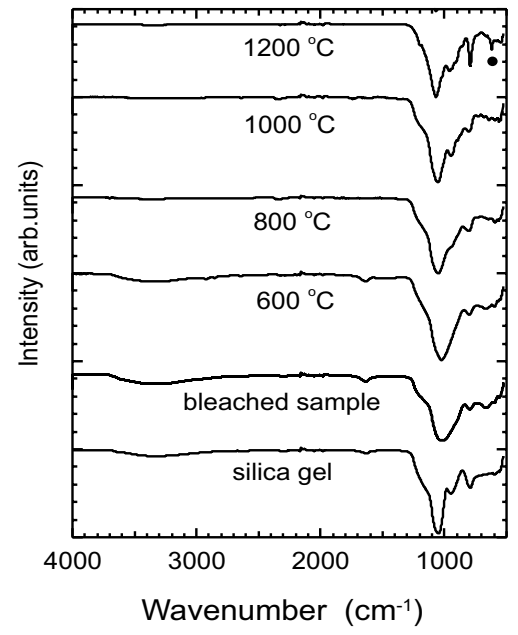

Fig. 3 The ATR-IR spectra for silica gel, bleached sample and heated samples. Solid circle is the peak of cristobalite (Etchepare et al. 1978)

the superposition of the several bands of $\mathrm{O}-\mathrm{H}$ stretching vibration of water molecules and silanol groups (Anedda et al. 2003; Davis and Tomozawa 1996). A band attributed to the $\mathrm{Si}-\mathrm{OH}$ stretching vibration of silanol (Kamiya et al. 2000) is clearly observed at $v=950 \mathrm{~cm}^{-1}$ in the spectrum for silica gel used in this study.

The band due to $\mathrm{Si}-\mathrm{O}$ stretching vibration is broader in the spectrum for the bleached sample than in that of the silica gel. However, this band becomes sharper with increasing temperature. The broad band at around $v=3000-3700 \mathrm{~cm}^{-1}$ are not observed above $800{ }^{\circ} \mathrm{C}$. After the thermal treatment at $1000{ }^{\circ} \mathrm{C}$, a new peak appears at around $v=960 \mathrm{~cm}^{-1}$. Moreover, the spectrum for the sample heated at $1200{ }^{\circ} \mathrm{C}$ has a band at $v=620 \mathrm{~cm}^{-1}$ which may be attributed to the band of typical low-cristobalite (Etchepare et al. 1978).

\section{Raman spectroscopic analysis}

The Raman spectra for the bleached and heated samples show a low $\mathrm{S} / \mathrm{N}$ ratio, and a signal is not obtained above $v=800 \mathrm{~cm}^{-1}$ because of strong luminescence. However, the bleached sample shows the distinct different spectrum from that of silica gel (Fig. 4). The spectrum for silica gel have a relatively sharp band at around $v=485 \mathrm{~cm}^{-1}$, denoted as $\mathrm{D}_{1}$ band (Galeener 1982a, 1982b). In contrast, the Raman spectrum of the bleached sample only shows a broad band centered at around $v=455 \mathrm{~cm}^{-1}$, which becomes sharper with thermal treatment at 800 and $1000{ }^{\circ} \mathrm{C}$. The Raman spectrum for the bleached sample heated at $1200{ }^{\circ} \mathrm{C}$ shows strong sharp bands around $v=405 \mathrm{~cm}^{-1}$. The well-crystalized low-cristobalite has the strongest Raman band around $v=421 \mathrm{~cm}^{-1}$ attributed to the six-membered ring in

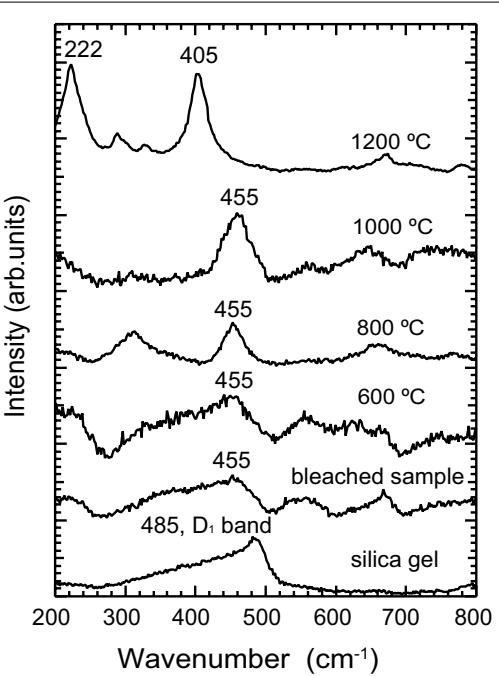

Fig. 4 Raman spectra for silica gel, bleached sample and heated samples

cristobalite structure (Kingma and Hemley 1994). Therefore, the Raman spectrum for the sample heated at $1200{ }^{\circ} \mathrm{C}$ may indicate the crystallization of sample to lowcristobalite, however, the Raman band of the heated sample located at $15 \mathrm{~cm}^{-1}$ lower than that of the position of the band reported by Kingma and Hemley (1994).

\section{Discussion}

Frustule structure of Chaetoceros calcitrans

The Raman spectrum for the bleached sample show the lack of the $D_{1}$ band and the presence of the broad band around $v=455 \mathrm{~cm}^{-1}$. It may indicate that the distribution of the ring structure may be different from silica gel. The four-membered ring may not be dominant in the structure of the bleached sample.

The position of the first sharp diffraction peak (FSDP) $(Q=4 \pi \sin \theta / \lambda)$ can be estimated from XRD data; this assists in evaluating the size of the medium-range structure (Elliott 1991). The variations in FSDP positions are listed in Table 1. Kamiya and Nasu (1998) elucidated that the medium-range structure of alkoxy-derived silica gel fibers and films based on the data obtained by NMR, and IR spectroscopies and XRD analysis and concluded that the network structure is mainly formed of a four-membered ring structure comprising $\mathrm{SiO}_{4}$ tetrahedra. This type structure for silica gel is also confirmed in this study by the presence of the strongest $D_{1}$ band observed in the Raman spectrum. The value of the FSDP position for silica glass $(Q=1.52)$ is lager than that for silica gel, which indicates that a six-membered ring structure is dominant in its network structure (Shimada et al. 2002). The value of the FSDP position for the bleached sample is $Q=1.59$, 
Table 1 FSDP positions $Q$ of X-ray scattering profiles for amorphous silica $(Q$ is $4 \pi \sin \theta / \lambda): \lambda$ is wavelength of X-ray)

\begin{tabular}{ll}
\hline Sample & $\mathbf{Q}\left(\AA^{-\mathbf{1}}\right)$ \\
\hline Bleached sample & 1.59 \\
Silica gel (used in this study) & 1.63 \\
Silica gel (Kamiya and Nasu 1998) & $1.60-1.70$ \\
Silica glass (Shimada et al. 2002) & 1.52 \\
\hline
\end{tabular}

and the order of $Q$ values is silica glass < bleached sample (diatom) < silica gel. These results indicate that the medium-range structure of the bleached sample may be smaller than that of silica glass but larger than that of silica gel. This result is consistent with that of Raman analysis.

A previous study revealed that silica gel and synthetic opal showed no evidence of crystallization during thermal treatment up to $1000{ }^{\circ} \mathrm{C}$ (Arasuna et al. 2013). On the other hand, the partial ordering to low-quartz or the formation of precursor of low-cristobalite may occur with thermal treatment at $800{ }^{\circ} \mathrm{C}$ for the bleached sample (see details below). It may indicate that the mediumrange structure of the bleached sample has the relatively ordered six-membered ring which observed in the lowquartz/cristobalite structure.

\section{Structural changes and crystallization of frustule}

Disappearance of the weak shoulder at around $2 \theta=5^{\circ}$ in the XRD profile for the sample heated at $600{ }^{\circ} \mathrm{C}$ indicates the decomposition of the residual organic matter. This event could be related to the sharpness of the IR band at around $v=1020 \mathrm{~cm}^{-1}$ in the spectrum for this sample. Moreover, this IR band becomes much sharper with increasing temperature, indicating the ordering of structures in the heated samples.

Well-ordered low-quartz has a strong Raman band at around $v=465 \mathrm{~cm}^{-1}$ (Kingma and Hemley 1994). Therefore, the Raman band (at around $v=455 \mathrm{~cm}^{-1}$ ) observed in the spectrum for the sample heated at $800{ }^{\circ} \mathrm{C}$ may indicate the possibility of the presence of partially ordered law-quartz in its structure, although this Raman band is considerably broader. Two weak diffraction peaks are observed in the XRD profiles for the sample heated at $800{ }^{\circ} \mathrm{C}$. The low-quartz has following diffraction peaks, the strongest peak located at $2 \theta=26.7^{\circ}$, the secondary peak at $2 \theta=20.9^{\circ}$ and smaller peaks at $2 \theta=36.6^{\circ}$ and $39.5^{\circ}$ and above $40^{\circ}$ (Levien et al. 1980). Therefore, the peaks observed in this sample cannot simply be attributed to the quartz structure. However, the weak peak at around $2 \theta=36^{\circ}$ is present in both the XRD profiles of low-cristobalite (around $36^{\circ}$; Graetsch 1994) and low-quartz (Levien et al. 1980; Graetsch 1994); therefore, the peak at around $2 \theta=35-36^{\circ}$ may be associated with low crystalline $\mathrm{SiO}_{2}$ material.

On the other hand, the Raman band at $v=455 \mathrm{~cm}^{-1}$ observed in the spectrum for the bleached sample is still observed after thermal treatment at $1000{ }^{\circ} \mathrm{C}$, although the stable $\mathrm{SiO}_{2}$ phase at this temperature is tridymite (Sosman 1927, 1955). Moreover, the XRD profile for the sample of $1000{ }^{\circ} \mathrm{C}$ shows the very weak peak at $2 \theta=22^{\circ}$ attributed to low-cristobalite (Graetsch 1994). These results may indicate that another following possibility for explanation for the Raman band at $v=455 \mathrm{~cm}^{-1}$. Amorphous $\mathrm{SiO}_{2}$ materials such as silica glass show the broad Raman band around $v=430-460 \mathrm{~cm}^{-1}$ attributed to the six-membered ring constituting amorphous network structure (Galeener and Geissberger 1983; Sharma et al. 1984; Okuno et al. 1999). Moreover, Shimoda et al. (2004) revealed that the Raman bands of a precursor crystal appeared at a position different from those of original material. Therefore, the Raman band at around $v=455 \mathrm{~cm}^{-1}$ is also possible to be a band for precursor for cristobalite. After all, we think that another precise structural study is necessary to explain all these data. On the other hand, six-membered ring is a basic structural unit of cristobalite and quartz. Therefore, more ordered six-membered ring observed in the structure of cristobalite/quartz could be present in the sample heated at $800-1000^{\circ} \mathrm{C}$. The crystallization temperature is relatively lower than those of silica gel and synthetic opal. Therefore, the bleached sample has the relatively ordered and dominant six-membered ring which observed in the lowquartz/cristobalite structure.

The ATR-IR band of silanol at $v=950 \mathrm{~cm}^{-1}$ observed in the spectrum for silica gel is unclear in the spectrum for the bleached sample because of the broadness of the $\mathrm{Si}-\mathrm{O}$ stretching band. However, the higher wavenumber side $\left(v>3600 \mathrm{~cm}^{-1}\right)$ of the broad band for $\mathrm{O}-\mathrm{H}$ stretching vibration at $v=3000-3700 \mathrm{~cm}^{-1}$ may indicate that the presence of silanol groups (Davis and Tomozawa 1996) in the structure of the bleached sample. Therefore, thermal treatment up to $800{ }^{\circ} \mathrm{C}$ is considered to result in dehydration of silanol groups and polymerization to form partially ordered structure.

A band appears at around $v=960 \mathrm{~cm}^{-1}$ in the ATRIR spectrum for the sample at $1000{ }^{\circ} \mathrm{C}$. As mentioned above, hydrous amorphous silica generally has the band of silanol at around this wavenumber region (Kamiya et al. 2000; Arasuna et al. 2013). However, the broad band $\left(v=3000-3700 \mathrm{~cm}^{-1}\right)$ relating to the presence of water molecules and silanol is not observed at this temperature. Thus, we presume that the band at $v=960 \mathrm{~cm}^{-1}$ is not related to silanol. In addition, decomposition of the residual organic material occurs at $600{ }^{\circ} \mathrm{C}$. Therefore, this 
band may be due to the $\mathrm{Si}-\mathrm{O}$ stretching band of newly formed relatively ordered structure.

In agreement with the results of XRD and ATR-IR measurements, the Raman spectrum of the sample heated at $1200{ }^{\circ} \mathrm{C}$ shows the crystallization to a lowcristobalite structure, although the stable phase of $\mathrm{SiO}_{2}$ between 870 and $1470{ }^{\circ} \mathrm{C}$ is tridymite (Sosman 1927, 1955). This phenomenon may be explained based on the Ostwald's step rule as observed in the report of the thermal experiment of synthetic opal (Arasuna et al. 2013). The difference of the Raman band position attributed to the six-membered ring of the cristobalite between the heated sample and the well-crystallized cristobalite indicates that heating at a higher temperature is necessary for bleached samples to completely crystallize to cristobalite.

\section{Conclusions}

In this study, we investigated the structural changes of bleached frustule of Chaetoceros calcitrans after thermal treatment using XRD analysis, ATR-IR and Raman spectroscopies. The information of structural change of frustule gave insight into the unheated nanostructure involved in ring structure in the bleached frustule.

The bleached sample heated at $800{ }^{\circ} \mathrm{C}$ shows release of water molecules and dehydration of silanol in the sample, resulting in the formation of a partially ordered low-quartz or the precursor of low-cristobalite. Sixmembered ring is basic structural unit of cristobalite and quartz. Therefore, it is presumed that the unheated structure of the bleached frustule has the relatively ordered and dominant six-membered ring in its structure. The frustule crystalized to low-cristobalite by heating at $1200^{\circ} \mathrm{C}$. However, additional heating is required for complete crystallization.

Our preliminary experiment indicated that there is a difference in the distribution of the Raman bands attributed to the ring structure for different types of diatom frustule. Therefore, the nanostructure of different diatoms living in seawater and other water environments (for example, in fresh water) will be investigated using mainly Raman spectroscopy in our future work.

\section{Authors' contributions}

AA carried out the thermal treatments for the samples and the analyses using XRD, ATR-IR and Raman spectroscopies for the samples. AA and MO discuss the obtained results and drafted the manuscript in cooperation. Both authors read and approved the final manuscript.

\section{Acknowledgements}

We are grateful to Dr. R. Jenkins and Mr. Y. Fukushima for SEM observation of non-bleached diatom. One of the author (AA) expresses her gratitude the support by Career Design Laboratory for Gender Equality, Kanazawa University.

\section{Competing interests}

The authors declare that they have no competing interests.
Availability of data and materials

The datasets during and analyzed during this study are available from the corresponding author on reasonable request.

Ethics approval and consent to participate

Not applicable.

\section{Funding}

This study was supported by the research funds of the Fukada Geological Institute (Japan)

\section{Publisher's Note}

Springer Nature remains neutral with regard to jurisdictional claims in published maps and institutional affiliations.

Received: 31 August 2017 Accepted: 2 January 2018

Published online: 12 January 2018

\section{References}

Anedda A, Carbonaro CM, Clemente F, Corda L, Corpino R, Ricci PC (2003) Surface hydroxyls in porous silica: a Raman spectroscopy study. Mater Sci Eng C 23:1069-1072

Arasuna A, Okuno M, Okudera H, Mizukami T, Arai S, Katayama S, Koyano M, Ito N (2013) Structural changes of synthetic opal by heat treatment. Phys Chem Miner 40:747-755

Arasuna A, Okuno M, Chen L, Mashimo T, Okudera H, Mizukami T, Arai S (2016) Shock-wave compression of silica gel as a model material for comets. Phys Chem Miner 43:493-502

Benesi HA, Jones AC (1959) An infrared study of the water-silica gel system. J Phys Chem 63:179-182

Davis KM, Tomozawa M (1996) An infrared spectroscopic study of water related species in silica glasses. J Non-Cryst Solids 201:177-198

Elliott SR (1991) Medium-range structural order in covalent amorphous solids. Nature 354:445-452

Etchepare J, Merian M, Kaplan P (1978) Vibrational normal modes of $\mathrm{SiO}_{2}$. II. Cristobalite and tridymite. J Chem Phys 68:1531-1537

Galeener FL (1982a) Planar rings in vitreous silica. J Non-Cryst Solids 49:53-62

Galeener FL (1982b) Planar rings in glasses. Solid State Commun 44:1037-1040

Galeener FL, Geissberger AE (1983) Vibrational dynamics in 30Si substituted vitreous $\mathrm{SiO}_{2}$. Phys Rev B 27:6199-6204

Gendron-Badou A, Coradin T, Maquet J, Frohlich F, Livage J (2003) Spectroscopic characterization of biogenic silica. J Non-Cryst Solids 316:331-337

Graetsch H (1994) Structural characteristics of opaline and microcrystalline silica minerals. Rev Mineral 29:209-232

Handke M, Mozgawa W (1993) Vibrational spectroscopy of the amorphous silicates. Vib Spectrosc 5:75-84

Inagaki Y (2011) Structural changes for diatom by heat treating and hydro thermal processing. Bachelor's thesis, Kanazawa University (In Japanese)

Isaacs CM (1982) Influence of rock composition on kinetics of silica phase changes in the monterey formation, Santa Barbara area, California. Geology 10:304-308

Kamiya K, Nasu H (1998) Structural and thermal change of alkoxy-derived silica gel fibers and films. Ceram Trans 81:21-28

Kamiya K, Oka A, Nasu H, Hashimoto T (2000) Comparative study of structure of silica gels from different sources. J Sol-Gel Sci Technol 19:495-499

Kingma KJ, Hemley RJ (1994) Raman spectroscopic study of microcrystalline silica. Am Mineral 79:269-273

Kröger N, Deutzmann R, Sumper M (1999) Polycationic peptides from diatom biosilica that direct silica nanosphere formation. Science 286:1129-1132

Levien L, Prewitt CT, Weidner DJ (1980) Structure and elastic properties of quartz at pressure. Am Mineral 65:920-930

Okuno M, Reynard B, Shimada Y, Syono Y, Willaime C (1999) A Raman spectroscopic study of shock-wave densification of vitreous silica. Phys Chem Miner 26:304-311 
Okuno M, Kitagawa Y, Asada R, Tazaki K (2003) Structural change of non-crystalline biogenic silica of diatoms by heat treatment. In: Tazaki K (ed) Water and soil environment. Kanazawa University, Kanazawa, pp 53-62

Sharma SK, Matson DW, Philpotts JA, Roush TL (1984) Raman study of the structure of glasses along the join $\mathrm{SiO}_{2}-\mathrm{GeO}_{2}$. J Non-Cryst Solids 68:99-114

Shimada Y, Okuno M, Syono Y, Kikuchi M, Fukuoka K, Ishizawa N (2002) An $\mathrm{X}$-ray diffraction study of shock-wave-densified $\mathrm{SiO}_{2}$ glasses. Phys Chem Miner 29:233-239

Shimoda K, Okuno M, Syono Y, Kikuchi M, Fukuoka K, Koyano M, Katayama S (2004) Structural evolutions of an obsidian and its fused glass by shockwave compression. Phys Chem Miner 31:532-542
Sosman RB (1927) The properties of silica. The chemical Catalog Company Inc, NewYork

Sosman RB (1955) New and old phase of silica. Trans Br Ceram Soc 54:655-670 Vrieling EG, Beelen TPM, van Santen RA, Gieskes WWC (1999a) Diatom silicon biomineralization as an inspirational source of new approaches to silica production. J Biotechnol 70:39-51

Vrieling EG, Gieskes WWC, Beelen TPM (1999b) Silicon deposition in diatoms: control by the $\mathrm{pH}$ inside the silicon deposition vesicle. J Phycol 35:548-559

Yamauchi I (2003) High-density mass culturing of Chaetoceros calcitrans as a valuable feed for aquaculture. Yamaha Mot Tech Rev 36:115-123 (in Japanese)

\section{Submit your manuscript to a SpringerOpen ${ }^{\circ}$ journal and benefit from:}

- Convenient online submission

- Rigorous peer review

- Open access: articles freely available online

- High visibility within the field

- Retaining the copyright to your article

Submit your next manuscript at springeropen.com 